\title{
Ambient analysis of liquid materials with Wet-SIMS
}

\section{AUTHOR(S):}

Seki, Toshio; Kusakari, Masakazu; Fujii, Makiko; Aoki, Takaaki; Matsuo, Jiro

\section{CITATION:}

Seki, Toshio ... [et al]. Ambient analysis of liquid materials with Wet-SIMS. Nuclear Instruments and Methods in Physics Research Section B: Beam Interactions with Materials and Atoms 2016, 371: 189-193

\section{ISSUE DATE:}

2016-03-15

URL:

http://hdl.handle.net/2433/245932

\section{RIGHT:}

(c) 2016. This manuscript version is made available under the CC-BY-NC-ND 4.0 license

http://creativecommons.org/licenses/by-nc-nd/4.0/; The full-text file will be made open to the public on 15 March 2018 in accordance with publisher's 'Terms and Conditions for Self-Archiving'; この論文は出版社版でありません。引用の際 には出版社版をご確認ご利用ください。; This is not the published version. Please cite only the published version. 


\section{Ambient Analysis of Liquid Materials with Wet-SIMS}

Toshio Seki (1), (4), Masakazu Kusakari (1), Makiko Fujii (2), Takaaki Aoki (3), (4) and Jiro

$$
\text { Matsuo (2), (4) }
$$

(1) Department of Nuclear Engineering, Kyoto University, Uji, 611-0011 Kyoto, Japan.

(2) Quantum Science and Engineering Center, Kyoto University, Uji, 611-0011 Kyoto, Japan.

(3) Department of Electronic Science and Engineering, Kyoto University, Nishikyo, 615-8510

$$
\text { Kyoto, Japan. }
$$

(4) SENTAN, Japan Science and Technology Agency (JST), Chiyoda, 102-0075 Tokyo, Japan

\section{Corresponding author: Toshio Seki}

Department of Nuclear Engineering, Kyoto Univ., Gokasyo, Uji, 611-0011 Kyoto, Japan.

e-mail: seki@sakura.nucleng.kyoto-u.ac.jp

phone: +81 774383977

Secondary ion mass spectrometry (SIMS) is a method with high surface sensitivity that allows both elemental and molecular analysis. However, volatile liquid (wet) samples are difficult to measure using conventional SIMS, because samples must be dried and introduced into a high vacuum chamber. The mean free path of ions with energy in the keV range is very short in low vacuum and these ions cannot penetrate the surface. In contrast, ions in the MeV-energy range have high transmission capability in low vacuum and wet samples can be measured using heavy ions without dry sample preparation. Ion beams in the MeV-energy range also excite electrons near the surface and enhance the ionization of high-mass molecules and thus fragment-suppressed SIMS spectra of ionized molecules can be obtained. We have developed an ambient analysis system with secondary ion mass spectrometry for wet samples (Wet-SIMS) that operates from low vacuum to $30 \mathrm{kPa}$ using MeV-energy heavy ion beams. The system is equipped with fine apertures that avoid vacuum degradation at both the primary 
beam incidence and the secondary ion measurement sides, even when the target chamber is filled with He gas at $30 \mathrm{kPa}$. Water evaporation was suppressed in a He atmosphere of 16.5 $\mathrm{kPa}$ and a solution of benzoic acid could be measured using MeV-energy heavy ions.

Keywords: SIMS; ambient analysis; MeV-energy heavy ion; water

\section{Introduction}

The solid-liquid interface is the most common interface encountered in electrochemical systems. The reactions on the electrode-electrolyte interface have to be investigated for performance improvement of electrochemical batteries and a suitable technology for analysis of liquid molecules near solid surfaces is needed for such an investigation. To analyze such a solid-liquid interface, an analysis system able to operate at ambient conditions is required, because liquid materials evaporate easily in vacuum. In addition, because the materials on the electrodes are molecular liquids with high mass, not only elemental analysis but also chemical state analysis with a high interface sensitivity is required. Particle-induced X-ray emission (PIXE) [1, 2], ambient pressure X-Ray photoelectron spectroscopy (AP-XPS) [3] and attenuated total reflectance Fourier transform infrared (ATR-FTIR) [4] spectroscopy have been used to analyze sample surfaces at ambient pressure. However, these techniques do not provide whole-molecule information such as molecular mass. Ambient mass spectrometry (MS) using desorption electrospray ionization (DESI) $[5,6]$ or matrix-assisted laser desorption/ionization (MALDI) [7, 8] have also been used for surface analysis, but these methods have low interface sensitivity, because a considerable volume must be sputtered for molecular analysis.

Secondary ion mass spectrometry (SIMS) is a method with high surface sensitivity that allows both elemental and molecular analysis. Recently, SIMS has been applied in molecular imaging of biological samples [9-13]. In a conventional SIMS that uses ion beams with 
energy in the keV range, elastic collisions occur between the projectiles in the beam and the atoms in the constituent molecules. The collisions break the molecules and produce fragments, making the acquisition of molecular information difficult. Moreover, volatile liquid (wet) samples are difficult to measure using conventional SIMS, because the samples must be dried and introduced into a high-vacuum chamber. The mean free path of ions with energy in the $\mathrm{keV}$ range is very short in low vacuum and these ions cannot penetrate the surface of the samples. In contrast, ion beams with MeV-energy excite electrons near the surface and enhance the ionization of high-mass molecules and thus fragment-suppressed SIMS spectra of ionized molecules can be obtained [14]. Wet samples can be measured using heavy ions in the MeV-energy range without dry sample preparation because of the high transmission capability of these ions at low vacuum pressure [15, 16]. For example, a TRIM (SRIM2013) calculation shows the projection range of the $6 \mathrm{MeV} \mathrm{Cu}^{+}$ion in $\mathrm{He}$ at atmospheric pressure to be about 35 $\mathrm{mm}$ [17]. However, the measurement has been performed at below $1 \mathrm{kPa}$ because of the problem of vacuum degradation at both the primary beam incidence and the secondary ion measurement sides. Materials with a relatively low vapor pressure (fatty acids, higher alcohols, etc.) can be measured at $1 \mathrm{kPa}$, but materials with a relatively high vapor pressure (water, lower alcohols, etc.) cannot. Water, in particular, is the most popular liquid and solution analysis is an inevitable requirement in the study of the liquid-solid interface. Therefore, we reviewed the structure of the target chamber and developed an ambient analysis system with SIMS for wet samples (Wet-SIMS) that operates from low vacuum to sub-atmospheric pressure $(<30 \mathrm{kPa}$ ) using heavy ion beams with $\mathrm{MeV}$-energy.

\section{Experimental}

SIMS measurements with $6 \mathrm{MeV} \mathrm{Cu}^{4+}$ were performed using an instrument equipped with an orthogonal acceleration (oa) time-of-flight (TOF) mass spectrometer, AccuTOF, JEOL, Japan $[18,19]$. The mass resolution $(\mathrm{m} / \Delta \mathrm{m})$ was typically about $6,000[14,20]$. For the 
ambient analysis the measurement system was equipped with fine apertures to avoid vacuum degradation. A schematic diagram of the ambient MeV-SIMS instrument is shown in Fig. 1. The orifice diameter of the the apertures was about $100 \mu \mathrm{m}$. The primary $6 \mathrm{MeV} \mathrm{Cu}^{4+}$ beam from the tandem accelerator was focused with a Q-lens and introduced onto the sample surface through an aperture. The sample was positioned in such a way that both the incident angle of the primary beam and the secondary ion extraction angle were $45^{\circ}$ with respect to the normal to the sample surface. The distance $\left(\mathrm{L}_{\mathrm{in}}\right)$ between the aperture and the sample surface was about $4 \mathrm{~mm}$. The secondary ions emitted from the sample were fed into the quadrupole ion guide section through another aperture and their mass was measured with the oaTOF.

The pressures of the primary beam line and the quadrupole ion guide sections are shown in Fig. 2 as a function of target chamber pressure. The target chamber was filled with He gas. To maintain high vacuum in the TOF analyzer, the pressure of the quadrupole ion guide section must be below $1 \mathrm{~Pa}$. Likewise, for normal operation of the quadrupole lens, the pressure on the primary beam line is expected to be below $1 \times 10^{-2} \mathrm{~Pa}$. In this system, even when the target chamber was filled with $\mathrm{He}$ gas at $30 \mathrm{kPa}$, the pressure on the primary beam line was less than $10^{-2} \mathrm{~Pa}$ and less than $10^{-1} \mathrm{~Pa}$ in the quadrupole ion guide sections; the pressure in the TOF analyzer was $\sim 10^{-5} \mathrm{~Pa}$. Thus, ambient analysis without vacuum degradation could be achieved. The voltages of the fine apertures ( $\mathrm{V}_{\text {in }}$ and $\left.\mathrm{V}_{\text {out }}\right)$ and the target $\left(\mathrm{V}_{\mathrm{t}}\right)$ were 40,30 and $34 \mathrm{~V}$, respectively.

\section{Results and discussion}

The SIMS spectra of lipids measured in the range $750 \mathrm{~Pa}-15,600 \mathrm{~Pa}$ are shown in Fig. 3. The measured samples were distearoyl-phosphatidylcholine (DSPC, $\mathrm{C}_{44} \mathrm{H}_{88} \mathrm{NO}_{8} \mathrm{P}$, Avanti Polar Lipids, Inc., USA). A DSPC chloroform solution of $10 \mu$ l was spin-coated on a Si wafer at $5000 \mathrm{rpm}$ for $30 \mathrm{~s}$. The acquisition time of the spectra was $10 \mathrm{~s}$. The signal peaks of the ion [Phosphatidylcholine (PC) headgroup $\left.\left(\mathrm{C}_{5} \mathrm{H}_{13} \mathrm{NO}_{4} \mathrm{P}\right)+2 \mathrm{H}\right]^{+}(\mathrm{m} / \mathrm{z}=184.1)$ and $[\mathrm{DSPC}+2 \mathrm{H}]^{+}$ 
$(\mathrm{m} / \mathrm{z}=790.6)$ were clearly detected with high sensitivity at the target pressures of 750 and 1,500 Pa. The PC headgroup is one of the most major fragments of PC. However, high noise peaks were detected in the $\mathrm{m} / \mathrm{z}$ range of $100-500$ at target pressures above $8.1 \mathrm{kPa}$. Details of the SIMS spectrum of Fig. 3(d) are shown in Fig. 4. The peaks were detected continuously in the $\mathrm{m} / \mathrm{z}$ range $150-250$ with $1 \mathrm{~m} / \mathrm{z}$ unit intervals. This result indicated that the noise was not electrical but chemical. The peaks of the ion $[\mathrm{PC} \text { headgroup }+2 \mathrm{H}]^{+}$were completely hidden among the noise peaks. The intensity of the chemical noise was about three orders of magnitude higher than at the target pressure of $750 \mathrm{~Pa}$. For ambient analysis the chemical noise must be reduced, and the origin of the chemical noise had to be identified. However, it is difficult to identify the origin from Fig. 4(a), because there are high peaks at all masses with $1 \mathrm{~m} / \mathrm{z}$ unit interval. On the other hand, some information could be obtained from major peaks in the $\mathrm{m} / \mathrm{z}$ range between 350 and 550 in Fig. 3(d). The interval of the peaks was $74 \mathrm{~m} / \mathrm{z}$ units. It can be guessed that these peaks originated from dimethylpolysiloxane $\left(\left(\mathrm{C}_{2} \mathrm{H}_{6} \mathrm{OSi}\right)_{n}\right)$ because the mass of $\mathrm{C}_{2} \mathrm{H}_{6} \mathrm{OSi}$ is $74 \mathrm{u}$. Dimethylpolysiloxane is used in vacuum grease. Figure 4(b) shows the spectrum with linear scale around the peaks of $m / z=371.1$ and 445.1 . It was found that the isotope distribution around $\mathrm{m} / \mathrm{z}=371.1$ was similar to that around $\mathrm{m} / \mathrm{z}=445.1$. The normalized isotope distributions of $\left[\left(\mathrm{C}_{2} \mathrm{H}_{6} \mathrm{OSi}\right)_{5}+\mathrm{H}\right]^{+}$and $\left[\left(\mathrm{C}_{2} \mathrm{H}_{6} \mathrm{OSi}\right)_{6}+\mathrm{H}\right]^{+}$is shown in Fig. 5(a). The calculated data was derived with an isotope distribution calculator (Scientific Instrument Service). Figure 5(b) shows the differences between the experimental and calculated values in Fig. 5(a). The differences were less than $3 \%$ in both cases of $\left[\left(\mathrm{C}_{2} \mathrm{H}_{6} \mathrm{OSi}\right)_{5}+\mathrm{H}\right]^{+}$and $\left[\left(\mathrm{C}_{2} \mathrm{H}_{6} \mathrm{OSi}\right)_{6}+\mathrm{H}\right]^{+}$. These results indicate that the peaks of $\mathrm{m} / \mathrm{z}=371.1$ and 445.1 were $\left[\left(\mathrm{C}_{2} \mathrm{H}_{6} \mathrm{OSi}\right)_{5}+\mathrm{H}\right]^{+}$and $\left[\left(\mathrm{C}_{2} \mathrm{H}_{6} \mathrm{OSi}\right)_{6}+\mathrm{H}\right]^{+}$, respectively. Therefore, one origin for chemical noise was vacuum grease. (The grease is used at the transfer rod of the load lock and the sliding parts of the scan stage). The vapor pressure of grease was very low and could not be detected with SIMS at the target pressure of 750 Pa. However, it was detected with high intensity at $15.6 \mathrm{kPa}$. It was assumed that the sensitivity to residual gas was extremely 
high and that the chemical noise originated from ionized residual gases. The ionization of residual gases was presumed to be generated in the region between the aperture at the primary beam incidence side and the sample surface, because He radicals generated by collision with primary ions can contribute to the ionization of residual gases.

To reduce chemical noise it is preferable to reduce the ionization region of residual gases. The ionization region can be reduced by decreasing the distance between the aperture at the primary beam incidence side and the sample surface $\left(\mathrm{L}_{\text {in }}\right)$. The intensity ratio of the molecular ion and the chemical noise from the DSPC sample at $\mathrm{L}_{\text {in }}=2 \mathrm{~mm}$ to that at $\mathrm{L}_{\text {in }}=4$ $\mathrm{mm}$ is shown in Fig. 6 . The summation of intensity in the $\mathrm{m} / \mathrm{z}$ range between 100 and 500 was regarded as chemical noise intensity. The target chamber pressure was $16.5 \mathrm{kPa}$. The ratio of the molecular ion $[\mathrm{DSPC}+\mathrm{H}]^{+}$was about 1.0 , whereas the ratio of chemical noise was 0.7 , indicating that chemical noise could be reduced by reducing the distance $\mathrm{L}_{\mathrm{in}}$.

The SIMS spectrum of the benzoic acid $\left(\mathrm{C}_{6} \mathrm{H}_{5} \mathrm{COOH}\right)$ solution at $16.5 \mathrm{kPa}$ is shown in Fig. 7. The concentration of benzoic acid solution was $30 \mathrm{mM}$ and the volume was $20 \mu \mathrm{L}$. The acquisition time of the spectra was $100 \mathrm{~s}$. The vapor pressure of water at $25^{\circ} \mathrm{C}$ is about $3.5 \times 10^{3} \mathrm{~Pa}$ [21]. If the solution sample is inserted in a vacuum of $50 \mathrm{~Pa}$, water evaporates quickly and the TOF measurement cannot be performed. In this experiment, the water droplet was kept in the target chamber for about 5 min. The dimer of benzoic acid and a compound of this acid with water were detected with high sensitivity because the intensity of these secondary ions from the benzoic acid solution was higher than the chemical noise. This result showed that water evaporation was suppressed in He gas at $16.5 \mathrm{kPa}$ and a solution of benzoic acid could be measured by the ambient analysis system with Wet-SIMS using MeV-energy heavy ions.

\section{Conclusion}


We have developed Wet-SIMS, an ambient analysis system that operates from low vacuum to $30 \mathrm{kPa}$ using $\mathrm{MeV}$-energy heavy ion beams. The system was equipped with fine apertures that avoid vacuum degradation at both the primary beam incidence and the secondary ion measurement sides, even when the target chamber was filled with He gas at 30 $\mathrm{kPa}$. Water evaporation was suppressed in He gas at $16.5 \mathrm{kPa}$ and a solution of benzoic acid could be measured using this setup.

\section{References}

1. S. Johansson, T. Johansson, Nucl. Instr. and Meth. 137 (1976) 473-516.

2. G. G. Seaman and K.C. Shane, Nucl. Inst. and Meth. 126 (1975) 473-474.

3. S. Axnanda, E. J. Crumlin, B. Mao, S. Rani, R. Chang, P. G. Karlsson, M. O. M. Edwards, M. Lundqvist, R. Moberg, P. Ross, Z. Hussain and Z. Liu, Scientific Reports 5 (2015) 9788.

4. Y. Arai1 and D. L. Sparks, J. Colloid and Interface Sci. 241 (2001) 317-326.

5. Z. Takáts, J. M. Wiseman, B. Gologan, and R. G. Cooks, Science 306(2) (2004) 471-473.

6. Z. Takáts, J. M. Wiseman and R. G. Cooks, J. Mass Spectrom. 40(10) (2005) 1261-1275.

7. V. V. Laiko, M. Baldwin, A. L. Burlingame, Anal. Chem. 72 (2000) 652-657.

8. V. V. Laiko, S. C. Moyer, and R. J. Cotter, Anal. Chem. 72 (2000) 5239-5243.

9. D. Touboul, O. Laprévote and A. Brunelle, Curr. Opin. Chem. Biol. 15 (2011) 725-732.

10. D. Touboul, F. Halgand, A. Brunelle, R. Kersting, E. Tallarek, B. Hagenhoff and O. Laprévote, Anal. Chem. 76 (2004) 1550-1559.

11. K. Börner, P. Malmberg, JE. Månsson, H. Nygren, Int. J. Mass. Spectrom. 260 (2007) $128-136$.

12. F. Kollmer, Appl. Surf. Sci. 231-232 (2004) 153-158.

13. A. Brunelle, D. Touboul and O. Laprévote, J. Mass. Spectrom. 40 (2005) 985-999. 
14. Y. Nakata, Y. Honda, S. Ninomiya, T. Seki, T. Aoki and J. Matsuo, J. Mass Spectrom. 44 (2009) 128-136.

15. J. Matsuo, S. Ninomiya, H. Yamada, K. Ichiki, Y. Wakamatsu, M. Hada, T. Seki, and T. Aoki, Surf. Interface Anal. 42 (2010) 1612-1615.

16. T. Seki, M. Fujii, M. Kusakari, S. Nakagawa, T. Aoki, J. Matsuo, Surf. Interface Anal. 46 (2014) 1133-1136.

17. J. Biersack and L. Haggmark, Nucl. Inst. and Meth. 174 (1980) 257-269.

18. Y. Wakamatsu, H. Yamada, S. Ninomiya, B. N. Jones, T. Seki, T. Aoki, R. Webb, and J. Matsuo, Nucl. Inst. and Meth. B 269 (2011) 2251-2253.

19. M. Guilhaus, D. Selby, and V. Mlynski, Mass Spectrom. Rev. 19(2) (2000) 65-107.

20. Y. Wakamatsu, H. Yamada, S. Ninomiya, B. N. Jones, T. Seki, T. Aoki, R. Webb, and J. Matsuo, AIP Conf. Proc. 1321 (2010) 233-236.

21. G. W. Thomson, Chem. Rev. 38 (1946) 1-39. 
List of table and figure captions

Figure 1

Schematic diagram of the ambient MeV-SIMS instrument.

Figure 2

The pressure of the primary beam line and the quadrupole ion guide sections as a function of target chamber pressure.

Figure 3

SIMS spectra of lipids (DSPC, $\mathrm{C}_{44} \mathrm{H}_{88} \mathrm{NO}_{8} \mathrm{P}$ ) measured in the range of 750-15,600 Pa.

Figure 4

Details of SIMS spectrum of Fig. 3(d). (a) Spectrum with logarithmic scale from $\mathrm{m} / \mathrm{z}=150$ to $m / z=250$. (b) Spectrum with linear scale around the peaks of $m / z=371.1$ and 445.1.

Figure 5

(a) Normalized isotope distributions of $\left[\left(\mathrm{C}_{2} \mathrm{H}_{6} \mathrm{OSi}\right)_{5}+\mathrm{H}\right]^{+}$and $\left[\left(\mathrm{C}_{2} \mathrm{H}_{6} \mathrm{OSi}\right)_{6}+\mathrm{H}\right]^{+}$. (b) Differences between the experimental and calculated values.

Figure 6

Intensity ratio of the molecular ion and chemical noise from DSPC sample from $\mathrm{L}_{\text {in }}=2$ to 4 $\mathrm{mm}$.

Figure 7

SIMS spectrum of benzoic acid solution in He of $16.5 \mathrm{kPa}$. 


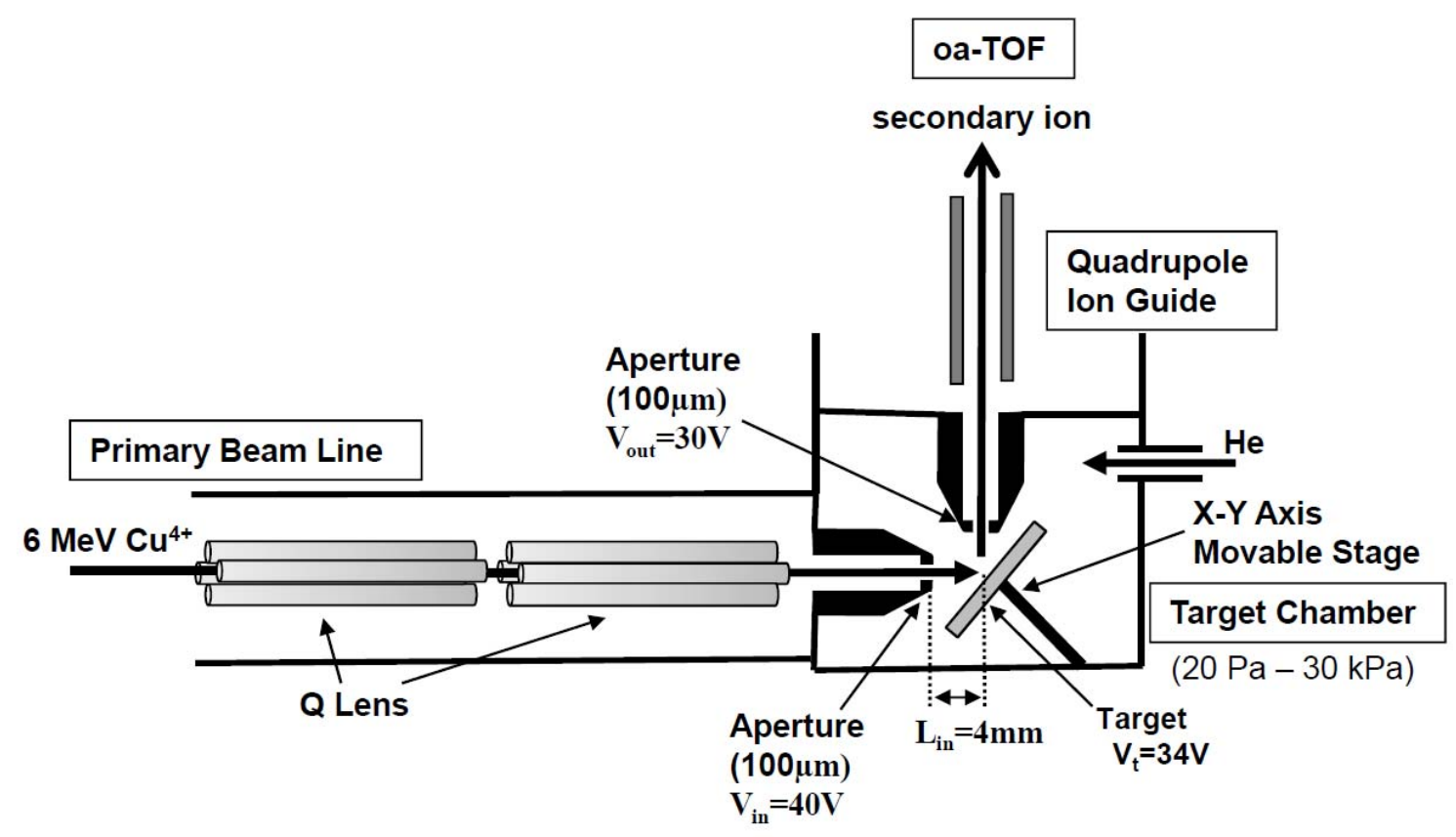

Figure 1 (1-column) 


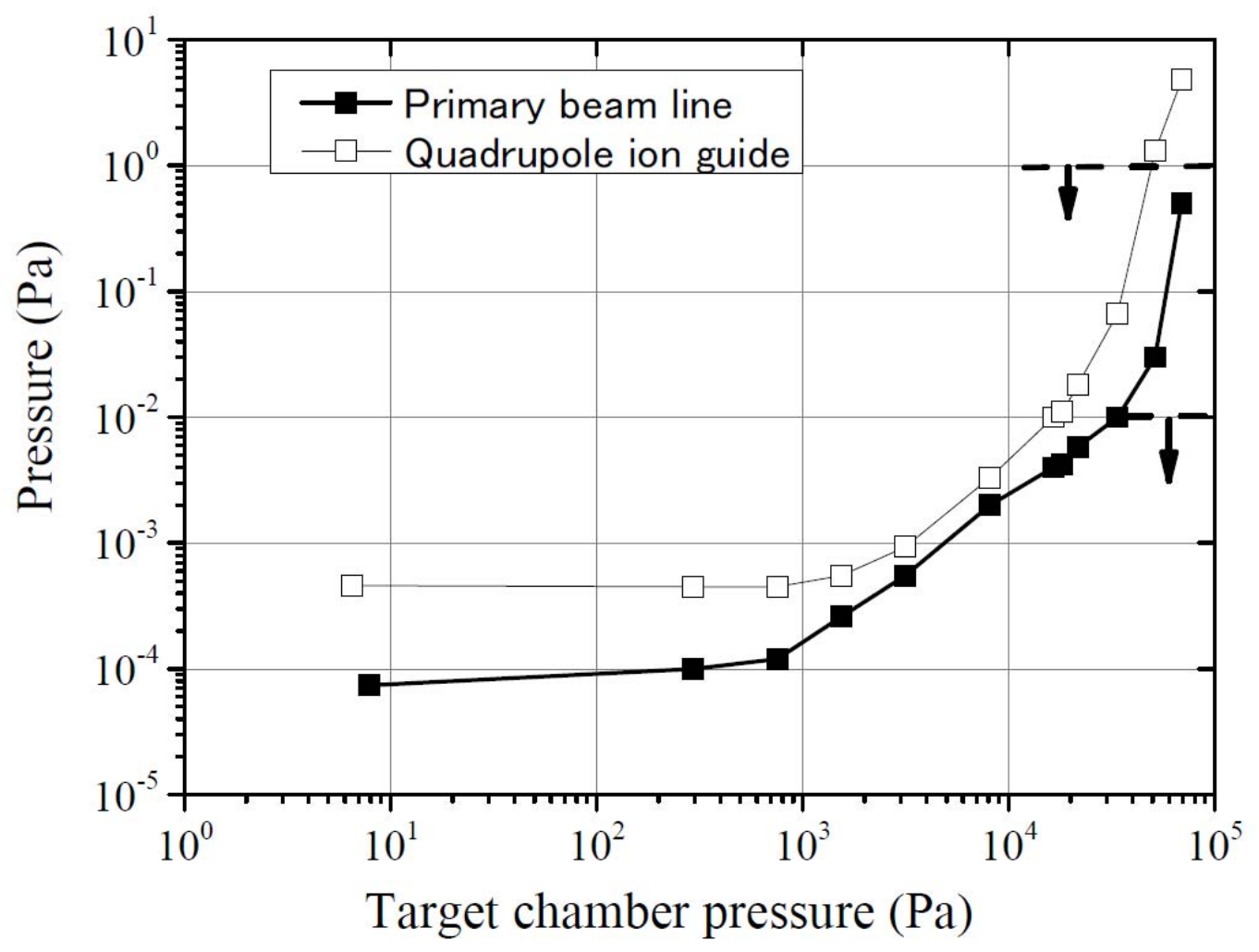

Figure 2 (1-column) 

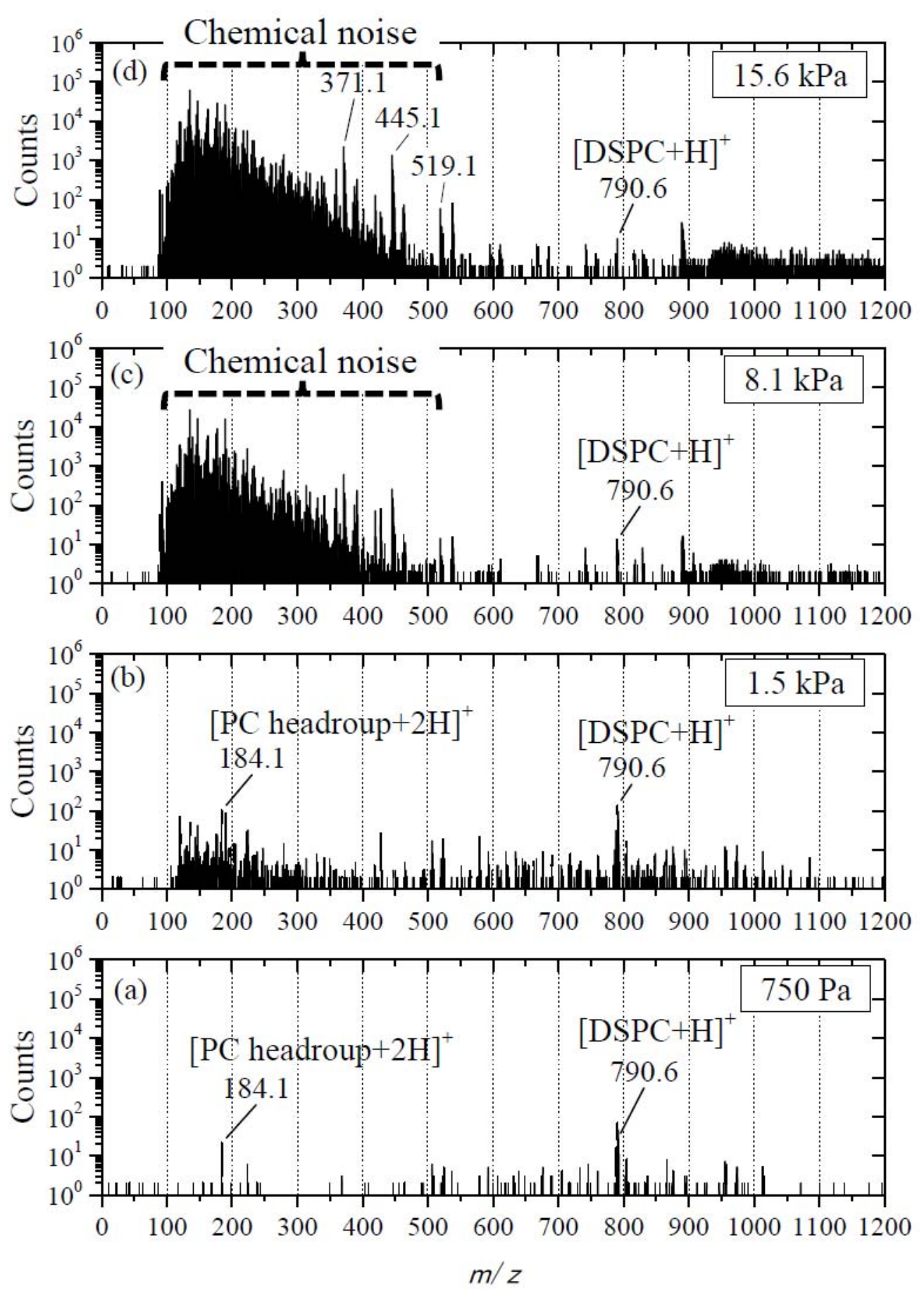

Figure 3 (1-column) 

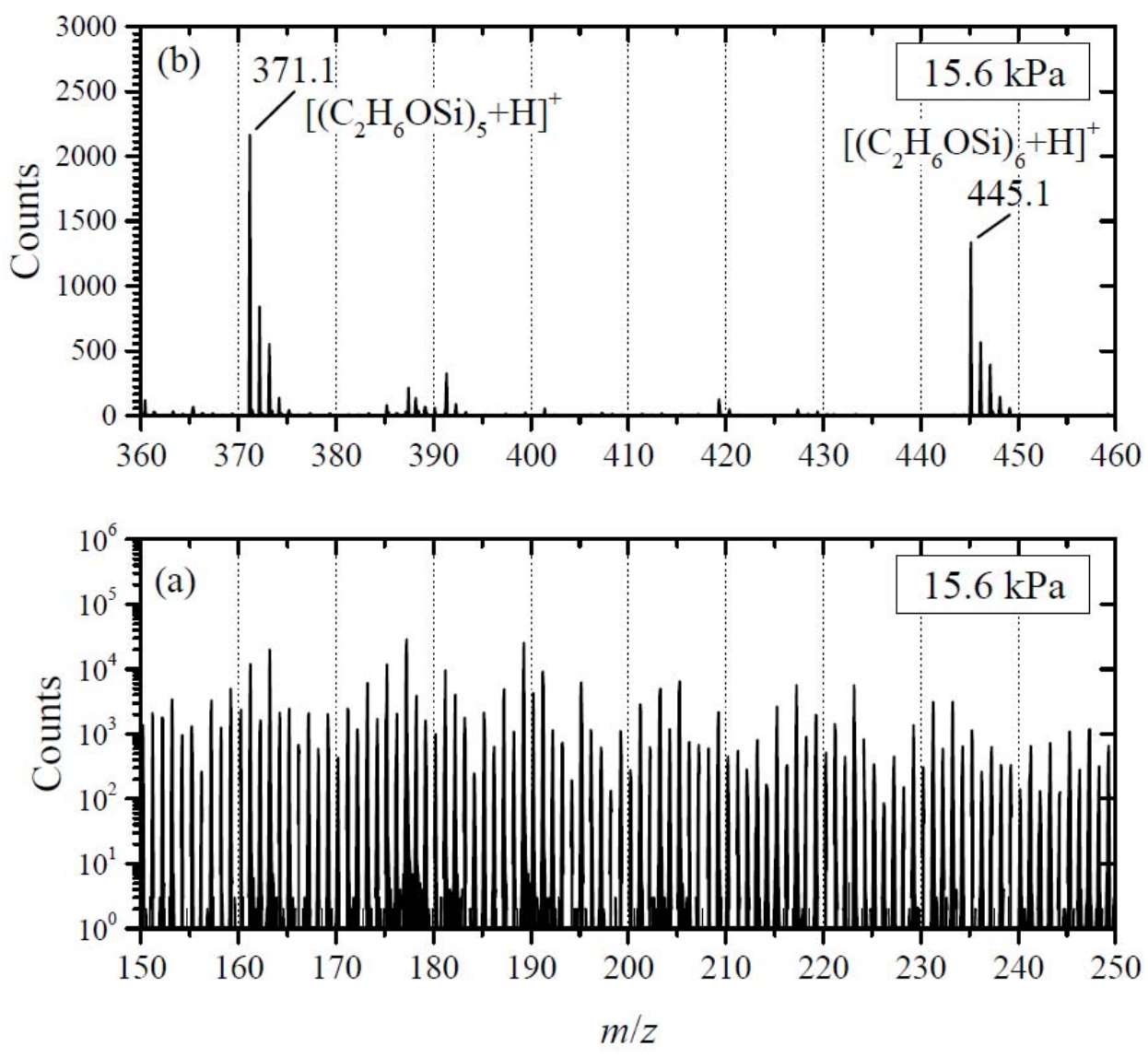

Figure 4 (1-column) 

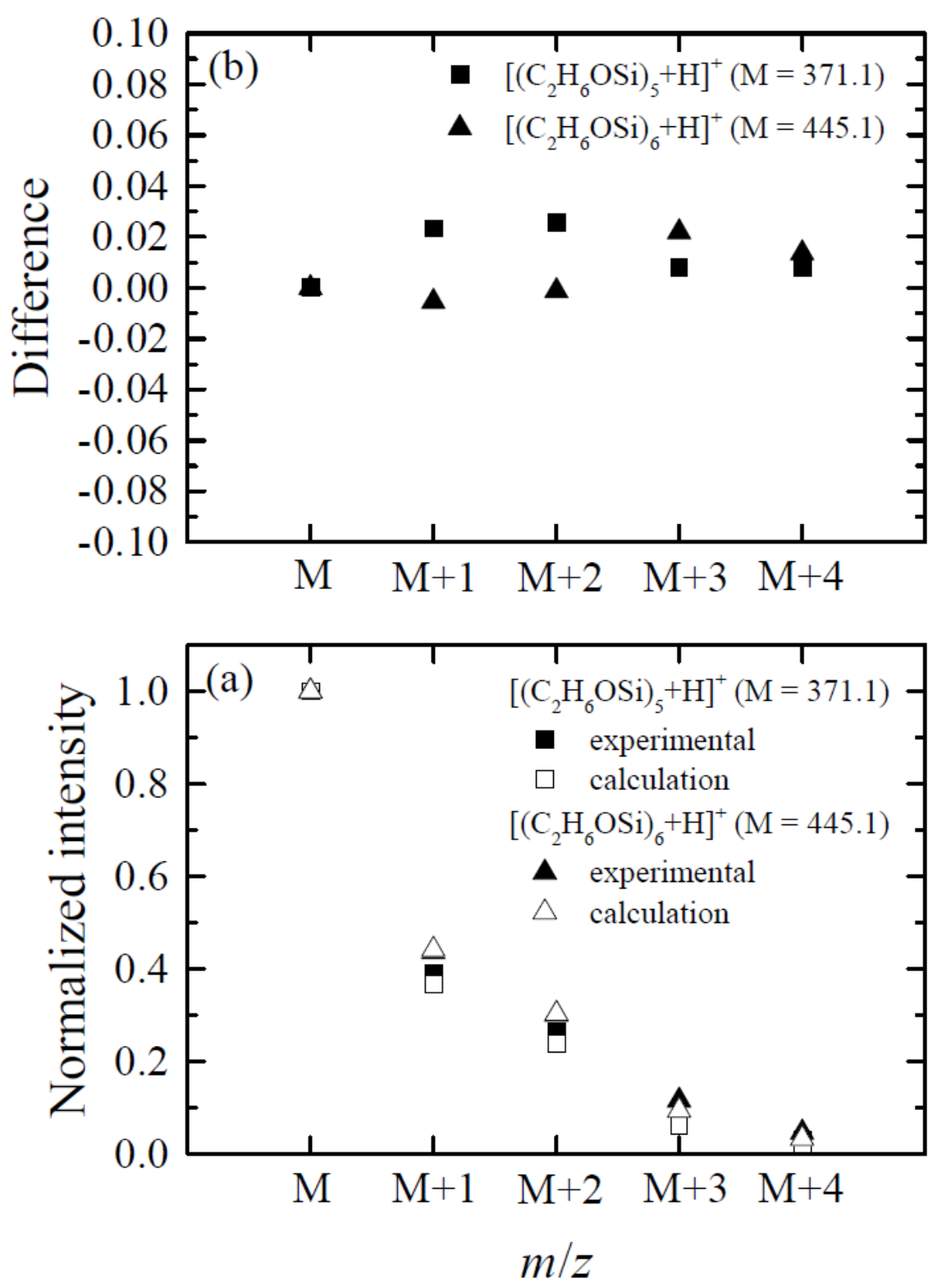

Figure 5 (1-column) 


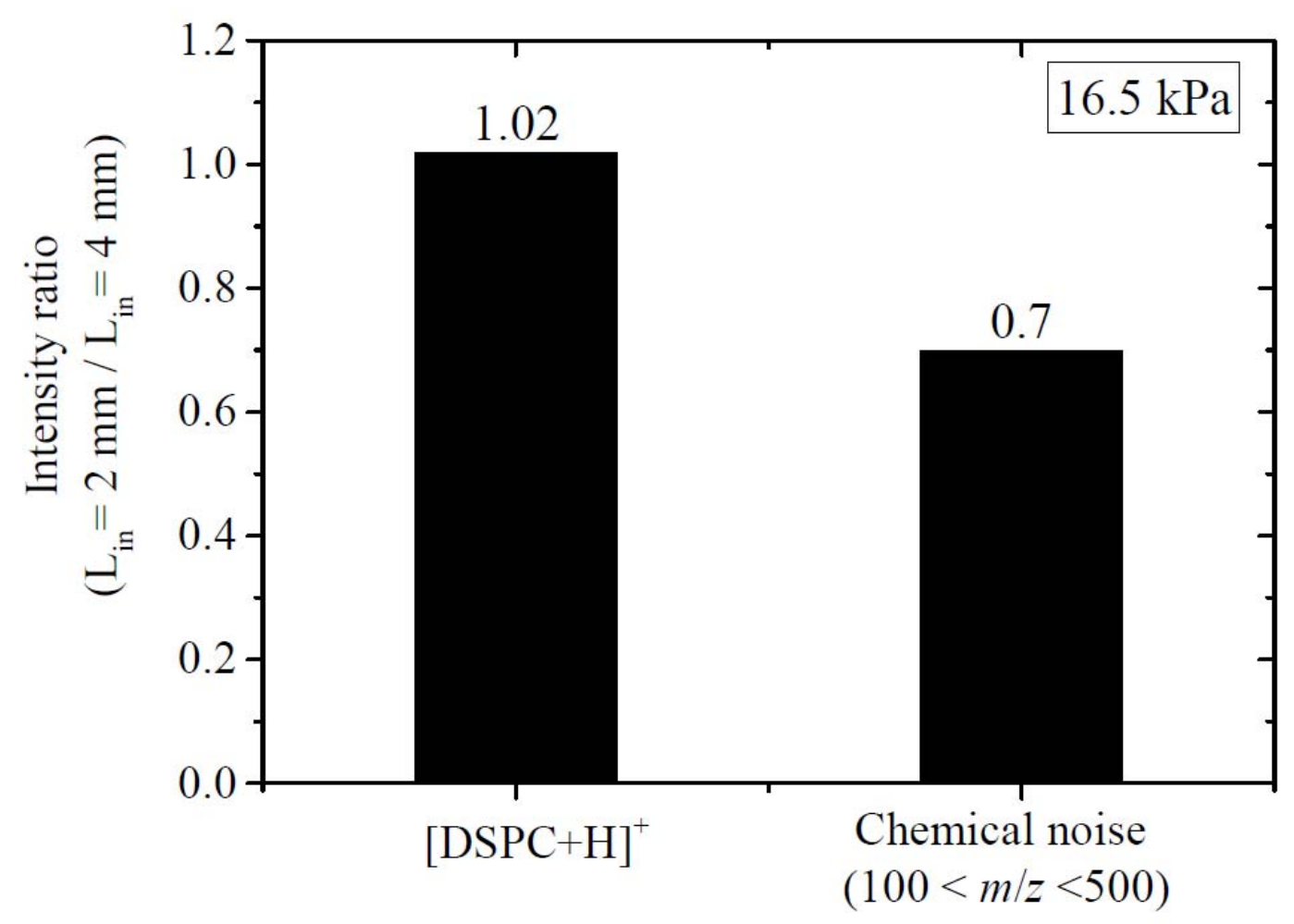

Figure 6 (1-column) 


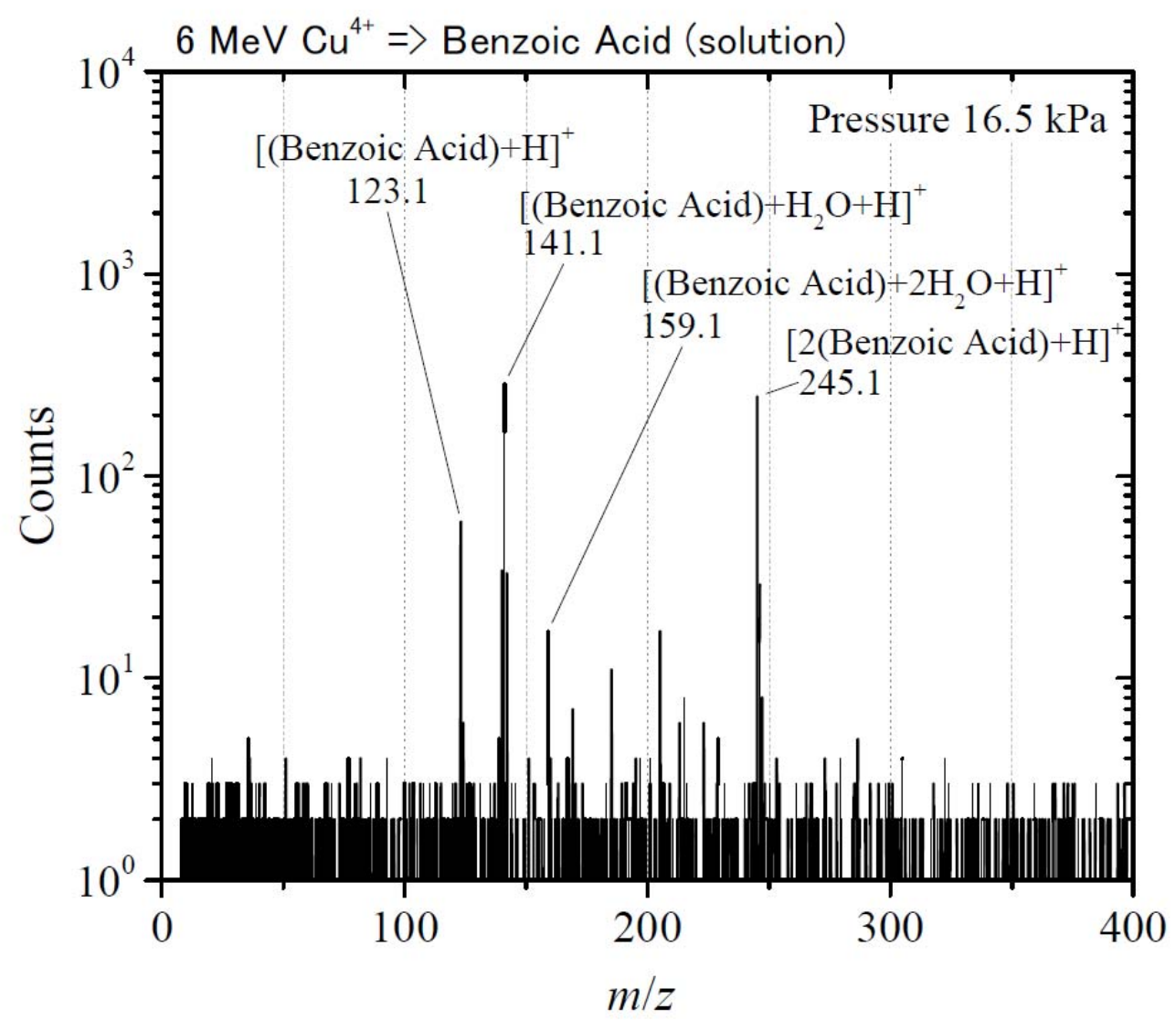

Figure 7 (1-column) 